\title{
Consentimento informado no atendimento pediátrico
}

\author{
Informed consent in pediatrics \\ Mário Roberto Hirschheimer ${ }^{1}$, Clóvis Francisco Constantino², Gabriel Wolf Oselka ${ }^{3}$
}

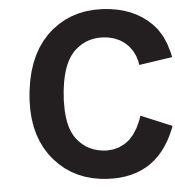

onsentimento informado é o registro em prontuário de uma decisão voluntária, por parte do paciente ou de seus responsáveis legais, tomada após um processo informativo e esclarecedor, para autorizar um tratamento ou procedimento médico específico, consciente de seus riscos, benefícios e possíveis consequências. Deve documentar que o paciente foi informado a respeito das opções de tratamento, se existirem.

Há diversas denominações usadas, em nosso meio, para se referir ao consentimento informado: "ciência e consentimento", "consentimento após informação", "consentimento livre e esclarecido", "consentimento pósinformação", "formulário de autorização de tratamento", "termo de aceitação do tratamento médico-cirúrgico ambulatorial", "termo de consentimento esclarecido", "termo de consentimento informado", "termo de esclarecimento e consentimento", "termo de esclarecimentos" e até o termo em inglês "informed consent" ${ }^{\text {"11). }}$

O bom atendimento médico, mesmo quando o desfecho é desfavorável, depende da empatia entre a equipe de saúde e o paciente e sua família. Fazer coincidir expectativas é um dos objetivos a alcançar nesse processo e, para tanto, a troca de informações entre as partes envolvidas é fundamental. O profissional de saúde obtém as informações de que necessita por meio de adequadas técnicas propedêuticas, das quais a anamnese é imprescindível. Por parte do paciente e sua família, as informações amplas e detaIhadas que o profissional da saúde é capaz de transmitir a respeito da doença são instrumentos imprescindíveis.

Para participar das decisões sobre sua saúde, o paciente ou seus responsáveis legais precisam ser esclarecidos sobre a enfermidade, seu prognóstico, a necessidade de exames complementares e de procedimentos e as opções terapêuticas com seus riscos, benefícios e custos $^{(2)}$. Essas informações devem ser abrangentes e em termos que possam ser entendidos pelo paciente ou por seus responsáveis legais.

Documentar que tais informações foram transmitidas e compreendidas é o espírito do consentimento informado. Ele expressa o respeito ao direito do paciente ou seus responsáveis legais de decidir, de modo esclarecido, a respeito de qualquer ato praticado para fins de diagnóstico e tratamento da doença. Nessa documentação, é impor- tante assinalar que, havendo o consentimento, este pode ser revogado a qualquer momento.

É dever do médico recomendar a conduta que considera a mais adequada, baseada nas melhores evidências disponíveis, mas respeitando o direito do paciente e de seus responsáveis legais de escolherem livremente as que mais Ihes convêm ao considerar seus próprios valores religiosos, espirituais, morais, éticos e culturais. Tal dever tem também implicações jurídicas nas esferas administrativa, cível e penal. Consentimento informado não é, portanto, mera formalidade para comprovar qualidade de atendimento por parte de instituições de acreditação hospitalar.

Algumas situações, entretanto, complicam tal processo. É o caso das emergências com risco de morte iminente ou de dano permanente e incapacitante. Nessas circunstâncias, no atendimento pediátrico, como a vida de crianças e adolescentes é o bem maior e é um dever prima facie preservá-la, o consentimento é considerado presumido. Outra situação ocorre quando o paciente é considerado incapaz, como os menores de idade e pacientes com enfermidades psiquiátricas ou com diminuição do nível de consciência, como doenças neurológicas ou intoxicações exógenas. Nesses casos, o consentimento cabe aos responsáveis legais do paciente (consentimento substitutivo ou proxy consent) ${ }^{(3)}$.

Mesmo sendo absolutamente (até os 16 anos) ou relativamente (dos 16 aos 18 anos) incapaz de exercer pessoalmente os atos da vida civil, o médico deve procurar incluir o paciente pediátrico nesse processo, à medida que ele se desenvolve e que for identificado como capaz de avaliar seu problema ${ }^{(4)}$. Assim, para realizar procedimentos ou tratamentos em crianças e adolescentes, recomenda-se obter o seu assentimento. O termo assentimento(5) é aqui empregado para diferenciá-lo do consentimento, que é fornecido por pessoas adultas e totalmente capazes para tomar decisões, segundo o Código Civil Brasileiro (Quadro 1)(6).

A capacidade de compreender as consequências de seus atos é um processo que normalmente se inicia a partir dos seis anos de idade e amadurece até o final da adolescência. Dessa forma, o menor tem direito a fazer opções sobre procedimentos diagnósticos e terapêuticos, embora, em situações consideradas de risco e frente à realização de procedimentos de alguma complexidade, tornam-se sempre necessários, além do assentimento do 
menor, a participação e o consentimento dos seus responsáveis legais ${ }^{(4)}$. A criança ou $o$ adolescente que se recusa a dar seu assentimento deve ser ouvida, especialmente se os benefícios esperados são incertos.

Obter o equilíbrio entre o consentimento substitutivo e o assentimento da criança ou do adolescente é importante para conseguir a empatia necessária entre a equipe de saúde e o paciente pediátrico e sua família, além de atender aos princípios éticos e legais do exercício profissional(2).

$\mathrm{Na}$ prática, quando existem divergências significativas, representando um conflito entre o princípio da beneficência (critérios da equipe de saúde) e o da autonomia (critérios do paciente e de seus responsáveis legais) e não há risco iminente de morte, deve-se expandir o diálogo para outros membros da equipe multiprofissional e da família (avós, tios etc.). Isso não significa capitulação do médico ou sua subjugação à decisão dos responsáveis legais do paciente $^{(2)}$.

No atendimento de adultos, esse direito prevalece em relação à vontade do profissional da saúde. Entretanto, no caso de crianças e adolescentes, a vontade dos seus responsáveis legais pode ser contestada na Justiça da Infância e Juventude se, a critério de quem atende o paciente, a decisão deles conflita com o melhor interesse do paciente menor de idade ${ }^{(1)}$.

É importante lembrar que a participação de crianças e adolescentes em protocolos experimentais é regulamentada pela Resolução 196/96 do Conselho Nacional de Saúde ${ }^{(7)}$, que determina a prévia apreciação de um termo de consentimento livre e esclarecido. Nos termos de tal resolução, as crianças e adolescentes não detêm o domínio da autonomia, devendo a autorização para participar em pesquisa ser fornecida pelos responsáveis legais, de maneira conjunta(8). O parágrafo único do artigo 101 do novo Código de Ética Médica ${ }^{(9)}$, aprovado na IV Conferência Nacional de Ética Médica em 29 de agosto de 2009, homologado pelo Conselho Federal de Medicina em 17 de setembro de 2009 (Resolução CFM n. ${ }^{\circ}$ 1.931/2009) e em vigor a partir de 13 de abril de 2010, prevê o assentimento do menor de idade considerado maduro para a realização de pesquisas envolvendo crianças e adolescentes (Quadro 2).

\section{Conflitos e dilemas}

Em atenção ao artigo 227 da Constituição da República Federativa do Brasil(10) e ao artigo $4^{\circ}$ do Estatuto da Criança e do Adolescente(11), os médicos e as instituições de Saúde devem representar a sociedade no dever de assegurar à criança e ao adolescente o direito à vida e à saúde. Essa responsabilidade existe independentemente dos pais ou de outros responsáveis legais (Quadro 3).

De acordo com o artigo 21 do Estatuto da Criança e do Adolescente ${ }^{(11)}$, o consentimento informado sempre deverá ser obtido de ambos os genitores, a não ser que um deles tenha sido afastado judicialmente desse direito. Entretanto, não é rara a impossibilidade de obter o consentimento de um ou de ambos os genitores, considerando-se as inúmeras situações de constituição familiar da sociedade contemporânea, como divórcios com guarda compartilhada dos filhos e possível litígio entre os responsáveis legais; um ou ambos os genitores (geralmente o pai) omissos ou ausentes e não-localizáveis; abrigo do menor por membro da família expandida (geralmente uma das avós) sem que tal guarda tenha sido legalmente estabelecida.

Se a equipe médica que atende o paciente concluir que a não-realização de algum procedimento poderá acarretar risco de morte, perda de qualidade de vida, perda de função de um determinado órgão ou sistema ou risco de sofrimento prolongado, a instituição de Saúde deve recorrer à Vara da Infância e Juventude de competência local para que as providências necessárias à proteção do paciente sejam tomadas nos casos de recusa dos pais para tal procedimento (Quadro 4) ${ }^{(11,12)}$.

Quadro 1 - Código Civil Brasileiro(6) ${ }^{(l e i ~ n .}{ }^{\circ} 10.406$, de 10 de janeiro de 2002).

Art. $3^{\circ}$ - São absolutamente incapazes de exercer pessoalmente os atos da vida civil:

I. Os menores de dezesseis anos;

II. Os que, por enfermidade ou deficiência mental, não tiverem o necessário discernimento para a prática desses atos;

III. Os que, mesmo por causa transitória, não puderem exprimir sua vontade.

Art. $4^{\circ}$ - São incapazes, relativamente a certos atos, ou à maneira de os exercer:

I. Os maiores de dezesseis e menores de dezoito anos;

II. Os ébrios habituais, os viciados em tóxicos, e os que, por deficiência mental, tenham o discernimento reduzido;

III. Os excepcionais, sem desenvolvimento mental completo;

IV. Os pródigos. 
Quadro 2 - Pesquisa em seres humanos.

Resolução n. ${ }^{0} 196 / 96$ do Conselho Nacional de Saúde(7), termo de consentimento livre e esclarecido para uso em protocolo de pesquisa envolvendo seres humanos.

O respeito devido à dignidade humana exige que toda pesquisa se processe após consentimento livre e esclarecido dos sujeitos, indivíduos ou grupos que por si ou por seus representantes legais manifestem a sua anuência à participação na pesquisa.

1. Exige-se que o esclarecimento dos sujeitos se faça em linguagem acessível e que inclua necessariamente os seguintes aspectos:

a) a justificativa, os objetivos e os procedimentos que serão utilizados na pesquisa;

b) os desconfortos e riscos possíveis e os benefícios esperados;

c) os métodos alternativos existentes;

d) a forma de acompanhamento e assistência, assim como seus responsáveis;

e) a garantia de esclarecimento, antes e durante o curso da pesquisa, sobre a metodologia, informando a possibilidade de inclusão em grupo controle ou placebo;

f) a liberdade do sujeito se recusar a participar ou retirar seu consentimento, em qualquer fase da pesquisa, sem penalização alguma e sem prejuízo ao seu cuidado;

g) a garantia do sigilo que assegure a privacidade dos sujeitos quanto aos dados confidenciais envolvidos na pesquisa;

h) as formas de ressarcimento das despesas decorrentes da participação na pesquisa; e

i) as formas de indenização diante de eventuais danos decorrentes da pesquisa.

2. O termo de consentimento livre e esclarecido obedecerá aos seguintes requisitos:

a) ser elaborado pelo pesquisador responsável, expressando o cumprimento de cada uma das exigências acima;

b) ser aprovado pelo Comitê de Ética em Pesquisa que referenda a investigação;

c) ser assinado ou identificado por impressão dactiloscópica, por todos e cada um dos sujeitos da pesquisa ou por seus representantes legais; e

d) ser elaborado em duas vias, sendo uma retida pelo sujeito da pesquisa ou por seu representante legal e uma arquivada pelo pesquisador.

3. Nos casos em que haja qualquer restrição à liberdade ou ao esclarecimento necessários para o adequado consentimento, devese ainda observar:

a) em pesquisas envolvendo crianças e adolescentes, portadores de perturbação ou doença mental e sujeitos em situação de substancial diminuição em suas capacidades de consentimento, deverá haver justificação clara da escolha dos sujeitos da pesquisa, especificada no protocolo, aprovada pelo Comitê de Ética em Pesquisa, e cumprir as exigências do consentimento livre e esclarecido, através dos representantes legais dos referidos sujeitos, sem suspensão do direito de informação do indivíduo, no limite de sua capacidade;

b) a liberdade do consentimento deverá ser particularmente garantida para aqueles sujeitos que, embora adultos e capazes, estejam expostos a condicionamentos específicos ou à influência de autoridade, especialmente estudantes, militares, empregados, presidiários, internos em centros de readaptação, casas-abrigo, asilos, associações religiosas e semelhantes, assegurando-lhes a inteira liberdade de participar ou não da pesquisa, sem quaisquer represálias;

c) nos casos em que seja impossível registrar o consentimento livre e esclarecido, tal fato deve ser devidamente documentado com explicação das causas da impossibilidade e parecer do Comitê de Ética em Pesquisa;

d) as pesquisas em pessoas com o diagnóstico de morte encefálica só podem ser realizadas desde que estejam preenchidas as seguintes condições:

- documento comprobatório da morte encefálica (atestado de óbito);

- consentimento explícito dos familiares e/ou do responsável legal, ou manifestação prévia da vontade da pessoa;

- respeito total à dignidade do ser humano sem mutilação ou violação do corpo;

- sem ônus econômico financeiro adicional à família;

- sem prejuízo para outros pacientes aguardando internação ou tratamento;

- possibilidade de obter conhecimento científico relevante, novo e que não possa ser obtido de outra maneira;

e) em comunidades culturalmente diferenciadas, inclusive indígenas, deve-se contar com a anuência antecipada da comunidade através dos seus próprios líderes, não se dispensando, porém, esforços no sentido de obtenção do consentimento individual;

f) quando o mérito da pesquisa depender de alguma restrição de informações aos sujeitos, tal fato deve ser devidamente explicitado e justificado pelo pesquisador e submetido ao Comitê de Ética em Pesquisa. Os dados obtidos a partir dos sujeitos da pesquisa não poderão ser usados para outros fins que os não previstos no protocolo e/ou no consentimento.

Código de Ética Médica - Resolução CFM n. ${ }^{0} 1.931 / 2009^{(9)}$

Capítulo XII - Ensino e Pesquisa Médica

Art. 101 - É vedado ao médico: deixar de obter do paciente ou de seu representante legal o termo de consentimento livre e esclarecido para a realização de pesquisa envolvendo seres humanos, após as devidas explicações sobre a natureza e as consequências da pesquisa.

Parágrafo único - No caso do sujeito de pesquisa ser menor de idade, além do consentimento de seu representante legal, é necessário seu assentimento livre e esclarecido na medida de sua compreensão. 


\section{Aspectos éticos e legais}

O consentimento informado é um dever do médico previsto nos artigos 22, 24, 31 e 34 do Código de Ética Médica ${ }^{(9)}$. O artigo 15 do Código Civil Brasileiro(6) é um reforço para sua obtenção, já que o exige para a execução de tratamentos e procedimentos com risco de vida(13) (Quadro 5). Deve-se, entretanto, considerar as diversas formas de relação médico-paciente que vêm se estabelecendo na nossa sociedade.

Embora o Código de Ética Médica(9) explicite que a natureza personalíssima da atuação profissional do médico não caracteriza relação de consumo, o Código de Defesa do

Quadro 3 - Direitos da criança e do adolescente.

Constituição da República Federativa do Brasil de
1988(10).

Art. 227 - É dever da família, da sociedade e do Estado assegurar à criança e ao adolescente, com absoluta prioridade, o direito à vida, à saúde, à alimentação, à educação, ao lazer, à profissionalização, à cultura, à dignidade, ao respeito, à liberdade e à convivência familiar e comunitária, além de colocá-los a salvo de toda forma de negligência, discriminação, exploração, violência, crueldade e opressão.

\section{Estatuto da Criança e do Adolescente ${ }^{(11)}$}

Art. $4^{\circ}$ - É dever da família, da comunidade, da sociedade em geral e do Poder Público assegurar, com absoluta prioridade, a efetivação dos direitos referentes à vida, à saúde, à alimentação, à educação, ao lazer, à profissionalização, à cultura, à dignidade, ao respeito, à liberdade, à convivência familiar e comunitária.

Art $5^{\circ}$ - Nenhuma criança ou adolescente será objeto de qualquer forma de negligência, discriminação, exploração, violência, crueldade e opressão, punido na forma da lei qualquer atentado por ação ou omissão aos seus direitos fundamentais.
Consumidor $^{(14)}$ e o Código Civil Brasileiro ${ }^{(6)}$ são claros no que se refere à necessidade das instituições de saúde (prestador de serviço) informar seus usuários (consumidor de serviços hospitalares) e obter seu consentimento previamente à efetivação de qualquer procedimento que o envolva (Quadro 6).

Em atenção ao artigo 422 do Código Civil Brasileiro (Quadro 7), pode-se dizer que o consentimento informado é uma manifestação objetiva da boa-fé do contratado (instituição de saúde) frente ao contratante (paciente) que, ao cumprir com o dever de informar e esclarecer, a demonstra por meio de documentação adequada, redigido da maneira clara e objetiva no prontuário do paciente(13).

\section{Recomendações}

Considerando o acima exposto, o Departamento de Bioética da Sociedade de Pediatria de São Paulo (SPSP) recomenda:

\section{Quadro 4 - Estatuto da Criança e do Adolescente(11).}

Art. 21 - O poder familiar será exercido, em igualdade de condições, pelo pai e pela mãe, na forma do que dispuser a legislação civil, assegurado a qualquer deles o direito de, em caso de discordância, recorrer à autoridade judiciária competente para solução da divergência.

Art. 33 - A guarda obriga à prestação de assistência material, moral e educacional à criança ou adolescente, conferindo $a$ seu detentor o direito de opor-se a terceiros, inclusive aos pais.

Parágrafo $2^{\circ}$ - Excepcionalmente, deferir-se-á a guarda, fora dos casos de tutela e adoção, para atender a situações peculiares ou suprir a falta eventual dos pais ou responsáveis, podendo ser deferido o direito de representação para a prática de atos determinados.

Quadro 5 - Direitos do paciente.

\author{
Código de Ética Médica, Resolução CFM n. ${ }^{0} 1.931 / 2009^{(9)}$. \\ Capítulo IV - Direitos Humanos \\ É vedado ao médico:
}

Art. 22 - Deixar de obter consentimento do paciente ou de seu representante legal após esclarecê-lo sobre o procedimento a ser realizado, salvo em caso de risco iminente de morte.

Art. 24 - Deixar de garantir ao paciente o exercício do direito de decidir livremente sobre sua pessoa ou seu bem-estar, bem como exercer sua autoridade para limitá-lo.

\title{
Capítulo V - Relação com Pacientes e Familiares
}

É vedado ao médico:

Art. 31 - Desrespeitar o direito do paciente ou de seu representante legal de decidir livremente sobre a execução de práticas diagnósticas ou terapêuticas, salvo em caso de iminente risco de morte.

Art. 34 - Deixar de informar ao paciente o diagnóstico, o prognóstico, os riscos e os objetivos do tratamento, salvo quando a comunicação direta possa provocar-lhe dano, devendo, nesse caso, fazer a comunicação a seu representante legal.

Código Civil Brasileiro(6) (lei n. ${ }^{0} 10.406$, de 10 de janeiro de 2002).

Art. 15 - Ninguém pode ser constrangido a submeter-se, com risco de vida, a tratamento médico ou à intervenção cirúrgica. 
Quadro 6 - Código de Ética Médica, Resolução CFM n. ${ }^{01.931 / 2009(9)}$.

\section{Capítulo I - Princípios Fundamentais}

XX - A natureza personalíssima da atuação profissional do médico não caracteriza relação de consumo.

Código de Defesa do Consumidor ${ }^{(14)}$ (lei n. ${ }^{\circ} 8.078$, de 11 de setembro de 1990).

Art. $6^{\circ}$ - São direitos do consumidor: (...)

III - a informação adequada e clara sobre os diferentes produtos e serviços (...);

Art. 31 - A oferta e a apresentação de produtos ou serviços devem assegurar informações corretas, claras, precisas, ostensivas e em língua portuguesa (...), bem como sobre os riscos que apresentem à saúde e segurança dos consumidores.

Art. 39 - É vedado ao fornecedor de produtos ou serviços dentre outras práticas abusivas: (...)

VI - executar serviços sem a prévia elaboração de orçamento e autorização expressa do consumidor.

Quadro 7 - Código Civil Brasileiro(6) ${ }^{(l e i ~ n .}{ }^{\circ} 10.406$, de 10 de janeiro de 2002).

Art. 422 - Os contratantes são obrigados a guardar, assim na conclusão do contrato, como na sua execução, os princípios de probidade e boa-fé.

Quadro 8 - Código Penal Brasileiro(16).

Art. 146 - Constranger alguém, mediante violência ou grave ameaça, ou depois de lhe haver reduzido, por qualquer outro meio, a capacidade de resistência, a não fazer o que a lei permite, ou a fazer o que ela não manda.

Parágrafo $3^{\circ}$ - Não se compreendem na disposição deste artigo:

I - a intervenção médica ou cirúrgica, sem o consentimento do paciente ou de seu representante legal, se justificada por iminente perigo de vida.

Quadro 9 - Parecer Consulta do CFM n² 24/97(17).

Aprovado em sessão plenária em 12/06/97, a Assessoria Jurídica do CFM, ao manifestar-se sobre a matéria, enfatizou os seguintes pontos:

I. O médico tem o dever de informar o paciente acerca dos riscos do ato médico e das consequências dos medicamentos que forem prescritos;

II. Além disso, o médico tem responsabilidade civil, penal e disciplinar sobre seus atos, devendo essa responsabilidade ser avaliada em cada caso;

III. O chamado "termo de consentimento esclarecido" tem como finalidade "formalizar" ou "documentar" o médico e, também, o paciente sobre as conseqüências que poderão advir do ato médico e da prescrição de medicamentos, inclusive hipóteses de caso "fortuito" e "força maior" desconhecidas da "Ciência" e que escapam ao controle da Medicina. Dessa forma, o aludido termo ou autorização não tem a virtude de excluir a responsabilidade do médico. Não pode ser entendido, pois, como excludente de responsabilidade ou cláusula de não-indenização;

IV. O aludido "documento" cumpre finalidade ético-jurídica e pode ser apreciado como "prova" da lisura do procedimento médico;

V. Assim, o "termo de consentimento esclarecido" jamais deverá ser de cunho impositivo, devendo ser sempre grafado em linguagem acessível e simples para entendimento do paciente que subscreverá o "documento", ou de seu representante legal.
1. Para participar das decisões sobre sua saúde, o paciente ou seus responsáveis legais precisam ser esclarecidos sobre a enfermidade que acomete o paciente, seu prognóstico, a necessidade de exames complementares e de procedimentos e as opções terapêuticas com seus riscos, benefícios e custos. Essas informações devem ser abrangentes e em termos que possam ser entendidos pelo paciente e por suas famílias. Só após assegurar que todas as questões relativas ao diagnóstico e tratamento da enfermidade foram esclarecidas e compreendidas, é possível o diálogo e, consequentemente, a tomada de decisões em conjunto(15).

2. Sendo os genitores os defensores dos interesses de seus filhos, são eles, em tese, que decidem, mas o assentimento das crianças e adolescentes nas decisões sobre sua saúde deve ser considerado, desde que o menor seja identificado pela equipe multiprofissional como capaz de avaliar seu problema.

3. Se for procedimento que visa preservar a vida (risco iminente de morte), o consentimento pode ser considerado presumido, o que é legalmente lícito ${ }^{(16)}$ e universalmente aceito (Quadro 8).

4. Quando existirem divergências ou conflitos entre o princípio da beneficência, defendida pela equipe de saúde, e o da autonomia da família, e não houver risco iminente de morte, deve-se ampliar o diálogo, envolvendo outros membros da equipe multiprofissional e da família expandida (avós, tios etc.).

5. Se não houver consenso, recorrer à decisão judicial por meio da elaboração de ofício à Vara da Infância e Juventude de atuação local, detalhando a situação, com o cuidado de usar uma linguagem acessível a não-médicos.

6. A elaboração específica do consentimento informado como documento do prontuário do paciente não é necessária, quando o procedimento diagnóstico e terapêutico já se constitui em consenso com regras explícitas e implícitas aplicadas em prática médica rotineira (embora com variações), baseada nas melhores evidências disponíveis. A existência de protocolos assistenciais ou diretrizes clíni- 
cas nas instituições de Saúde se constitui em importante instrumento de amparo para essa atitude.

7. O consentimento informado pode ser obtido verbalmente, sem a assinatura do paciente ou de seus responsáveis legais expressas em documento específico. Nesse caso, a reunião do paciente ou seus responsáveis legais com os membros da equipe multidisciplinar que transmitiram os esclarecimentos e obtiveram o consentimento deve ser detalhadamente registrada no prontuário do paciente, de preferência subscrita também por testemunhas que participaram da reunião. Isso se justifica, no nosso meio, não só pelo pouco entendimento da linguagem escrita de parcela significativa da população (analfabetismo funcional), mas também pelas situações nas quais a obtenção da assinatura no documento possa ser interpretada como uma forma de constrangimento(1).

8. Quando se optar pela formalização em prontuário do consentimento informado por meio de um documento específico, este não pode ser um documento padrão para todos os procedimentos, pois a diversidade de situações na Medicina

\section{Referências bibliográficas}

1. Constantino CF, Barros JCR, Hirschheimer MR, Monteiro PJC. Prontuário do paciente. In: Constantino CF, Barros JCR, Hirschheimer MRH, editores. Cuidando de crianças e adolescentes sob o olhar da ética e da bioética. Rio de Janeiro: Atheneu; 2009. p. 203-13.

2. Pessoa JHL. O atendimento pediátrico. In: Constantino CF, Barros JCR, Hirschheimer MRH, editores. Cuidando de crianças e adolescentes sob o olhar da ética e da bioética. Rio de Janeiro: Atheneu; 2009. p. 1-16.

3. Kipper DJ. Uma introdução à bioética. In: Kipper DJ, editor. Temas de pediatria 73. São Paulo: Nestlé; 2002. p. 1-56.

4. Françoso LA, Oselka GW. Aspectos éticos do atendimento do adolescente. Atualize-se pediatra SPSP 1999;10:4.

5. American Academy of Pediatrics, Committee on Bioethics. Informed consent, parental permission, and assent in pediatric practice. Pediatrics 1995;95:314-7.

6. Brasil. Código Civil Brasileiro. Lei n 10.406, de 10 de janeiro de 2002.

7. Brasil - Ministério da Saúde. Conselho Nacional de Saúde. Resolução nº 196. Brasília, DF: Ministério da Saúde, de 10 de outubro de 1996.

8. Kopelman BI, Constantino CF, Torreão LA, Hirschheimer MR, Cipolotti R, Krebs VLJ. Bioética e pediatria. In: Lopez FA, Campos Jr. D, editores. Tratado de pediatria. $2^{\mathrm{a}}$ ed. Barueri: Manole; 2010. p.15-25. é tamanha que a previsão delas num único documento é impossível. O Parecer Consulta do CFM n. ${ }^{\circ} 24 / 97$ (Quadro 9) ${ }^{(17)}$ esclarece que compete às instituições de saúde elaborar os referidos formulários e submetê-los à avaliação da Comissão de Ética e, quando necessário, ao próprio Conselho Regional de Medicina. Além dos esclarecimentos médicos específicos pertinentes ao procedimento proposto, nele devem constar: identificação do paciente; identificação (com documento de identidade) e assinatura dos responsáveis legais (geralmente ambos os genitores); identificação (com o número do CRM) do médico que prestou os esclarecimentos e obteve o consentimento; cláusula que explicite que o consentimento é revogável a qualquer momento se o paciente ou seus responsáveis legais assim o desejarem.

9. A formalização do termo de consentimento livre e esclarecido como constituinte do prontuário do paciente é obrigatória para aplicação de tratamentos inovadores, não padronizados, com riscos e benefícios indefinidos, conforme a Resolução n. ${ }^{0}$ 196/96, do Conselho Nacional de Saúde (Quadro 2) ${ }^{(7)}$.

9. Conselho Federal de Medicina. Código de Ética Médica. Resolução CFM n. ${ }^{\circ}$ 1931/2009. Diário Oficial da União - DOU de 24 de setembro de 2009 Seção I, p. 90 e retificação publicada no Diário Oficial da União - DOU de 13 de outubro de 2009, Seção I, p. 173.

10. Brasil. Constituição da República Federativa do Brasil, de 05 de outubro de 1988.

11. Brasil. Estatuto da Criança e do Adolescente. Lei n. ${ }^{\circ} 8.069$, de 13 de julho de 1990.

12. Constantino CF, Oselka GW, Hirschheimer MR. Alta a pedido. In: Constantino CF, Barros JCR, Hirschheimer MRH, editores. Cuidando de crianças e adolescentes sob o olhar da ética e da bioética. Rio de Janeiro: Atheneu; 2009. p. 197-202.

13. Boyaciyan K, Vásquez MO. Regulamentação civil da autonomia do paciente. JAMB 2007;48:24.

14. Brasil. Código de Defesa do Consumidor. Lei $n .^{\circ} 8.078$, de 11 de setembro de 1990.

15. Duch LF. Criança com malformações. In: Oselka GW, coordenador. Bioética clínica: reflexões e discussões sobre casos selecionados. São Paulo: Cremesp; 2008. p. 171-6

16. Brasil. Código Penal. Decreto-Lei n. ${ }^{\circ} 2.848$, de 07 de dezembro de 1940.

17. Conselho Federal de Medicina. Parecer-Consulta CFM n. ${ }^{\circ} 3.528 / 94$ - PC/ CFM/n. ${ }^{\circ}$ 24/97, aprovado em 12/06/97.

Instituição: Departamento de Bioética da Sociedade de Pediatria de São Paulo (SPSP), São Paulo, SP, Brasil

${ }^{1}$ Médico Pediatra; Assessor Técnico Médico do Hospital Municipal Infantil Menino Jesus da Prefeitura do Município de São Paulo; Médico Responsável pela UTI do Pronto-Socorro Infantil Sabará - São Paulo. Presidente do Departamento de Bioética da SPSP; Membro do Departamento de Cuidados Hospitalares da Sociedade Brasileira de Pediatria, São Paulo, SP, Brasil

${ }^{2}$ Doutorando em Bioética pela Faculdade de Medicina da Universidade do Porto - Portugal - FMUP/CFM; Médico Pediatra; Presidente da Sociedade de Pediatria de São Paulo; Conselheiro Vice-corregedor do CREMESP; Membro do Departamento de Bioética da SPSP; Secretário do Departamento de Bioética da SBP.

${ }^{3}$ Médico Pediatra; Membro do Departamento de Bioética da SPSP.
Conflito de interesse: nada a declarar

Endereço para Correspondência:

Mario Roberto Hirschheimer

Al. Santos, 211, cj. 511

CEP 01419-000 - São Paulo/SP

E-mail: spsp@spsp.org.br

Recebido em: 23/02/2010 